\title{
Females learn from mothers and males learn from others. The effect of mother and siblings on the development of female mate preferences and male aggression biases in Lake Victoria cichlids, genus Mbipia
}

\author{
Machteld N. Verzijden • R. E. Madeleine Korthof • \\ Carel ten Cate
}

Received: 25 May 2007 /Revised: 6 February 2008 / Accepted: 8 February 2008 /Published online: 6 March 2008

(C) The Author(s) 2008

\begin{abstract}
While species-assortative behaviour is often observed in sympatrically occurring species, there are few examples where we understand the extent to which development of assortative behaviour is genetically or environmentally determined, for instance, through learning. However, the majority of mate choice theory assumes genetic recognition mechanisms. Knowledge about the development of species recognition is important for our understanding of how closely related species can coexist and how this coexistence may have arisen. The ontogeny of female mate choice, for instance, may critically influence the degree of assortative mating under many circumstances. Also, male assortative aggression behaviour may affect fitness and the possibility for coexistence of two closely related species. Here, we test whether male aggression biases and female mate preferences of two Lake Victoria rock cichlid species, Mbipia mbipi and Mbipia lutea, are affected by experience. With an interspecific cross-fostering experiment, we test for the effect of experience with the phenotype of the mother and that of the siblings on speciesassortative mate preferences and aggression biases. We demonstrate that female mate preferences are strongly
\end{abstract}

Communicated by C. Gabor

M. N. Verzijden · R. E. M. Korthof · C. ten Cate

Behavioural Biology, Leiden University,

Leiden, The Netherlands

M. N. Verzijden $(\bowtie)$

Department of Biology, Texas A\&M University,

3258 TAMU,

College Station, TX 77843-3258, USA

e-mail: mverzijden@mail.bio.tamu.edu influenced by learning about their mothers' phenotype but not by experience with their siblings, despite ample opportunity for interactions. Male aggression biases, in contrast, are affected by experience with siblings but not by learning about their mothers' phenotype. We suggest that the development of assortative behaviour of females, but not of males, creates favourable conditions for sympatric speciation in Lake Victoria cichlids.

Keywords Sexual imprinting - Rival imprinting · Speciation · East African cichlids

\section{Introduction}

Stable coexistence of closely related species can occur, but only when reproductive isolation prevents hybridisation and when there is a source of negative frequency-dependent selection to maintain both species (e.g. Dieckmann and Doebeli 1999; van Doorn et al. 2004; Rueffler et al. 2006). Reproductive isolation is mediated by preferences for conspecifics as potential mates. However, individuals of species that share their habitat with closely related species face the every-day problem of deciding whom to interact with. How do individuals develop the selectivity to interact preferentially with conspecifics? Several developmental mechanisms can produce such assortative preferences, ranging from a fully genetically controlled development to fully environmentally determined preferences (Shaw 2000; Riebel 2003). Some of these mechanisms, however, will not produce assortative behaviour in all circumstances, while other mechanisms may particularly easily produce species-assortative interactions under many 
circumstances (Dieckmann and Doebeli 1999; Servedio 2000; Arnegard and Kondrashov 2004; van Doorn et al. 2004; Beltman and Metz 2005; Verzijden et al. 2005). The developmental mechanism behind preferences and biases in social interactions may therefore play a pivotal role in the evolution of species-assortative behaviour and, therefore, speciation. The study of its development may help us understand these processes.

To keep one species from out-competing the other one, or to prevent chance fluctuations in population size to eliminate one of the species, a source of negative frequency-dependent selection is needed (reviews in Kirkpatrick and Ravigne 2002; Rueffler et al. 2006), which may maintain both phenotypes and also drive the evolution of new species. Natural selection through competition over resources may be one such source. An alternative or an additional source for frequency-dependent selection has been indicated in male-male competition (Mikami et al. 2004; Seehausen and Schluter 2004; van Doorn et al. 2004). Males may be better off by selectively fighting only with males that compete for the same females or resources, thus resulting in assortative male-male interactions in many cases. Male aggressive behaviour could therefore also exert selection on species specific phenotypes (e.g. Alatalo et al. 1994; Seehausen and Schluter 2004; Tynkkynen et al. 2005). When males compete selectively with other males that are of a similar phenotype as themselves, rare phenotypes would have fewer aggressive encounters than the common phenotype and, therefore, incur lower costs to obtain and maintain a territory (Seehausen and Schluter 2004). The reduced male-male competition for rare phenotypes should then result in increased mating opportunities. Speculating on how this may be achieved; males may be able to invest more in courtship, or may be preferred by females, for instance, because they are in better condition after less fighting (Wong and Candolin 2005). A rare-male advantage arises from strictly assortative male-male interactions, thus, proximately mediated by the development of selective male aggression. When the development of species recognition is particularly geared towards producing assortative malemale interactions, i.e. is not susceptible to fluctuations in the distribution of phenotypes in the population, frequencydependent effects could occur.

Although the occurrence of species-assortative behaviour is relatively common, in comparison, only a few studies have looked at what developmental mechanism mediates it and, if so, then often only in one of the sexes (fish: Engeszer et al. 2004; Verzijden and ten Cate 2007; songbirds: ten Cate and Vos 1999; Slagsvold et al. 2002; Hansen and Slagsvold 2003; Riebel 2003; corn borer moths: Roelofs et al. 1987; crickets: Shaw 2000; Ritchie 2000; fruit flies: overview in Coyne and Orr 2004). As a consequence, our understanding of the possible evolution- ary trajectories leading to assortative behaviour and reproductive isolation is limited. One developmental mechanism mediating mate preferences that is found in several species is sexual imprinting. This form of learning occurs early in life. When sexual imprinting occurs, young learn about a parental phenotype as a model for their later preferences for mates (Kendrick et al. 1998; ten Cate and Vos 1999; Bereczkei et al. 2004; Verzijden and ten Cate 2007). This mechanism matches an individual's preference to the parental phenotype. High genetic, and therefore phenotypic, similarity between parent and offspring appearance will ensure a relatively good match of social preferences and own phenotype. While often studied in the context of mate preferences, male-male interactions may also be mediated by imprinting, called rival imprinting (Vos 1994; Hansen and Slagsvold 2003). Juvenile males then learn about their parents' phenotype as a model for later rivals. Alternatively, a genetic predisposition for 'own type' bias may also provide assortative social interaction patterns. In contrast, learning from encounters with less related individuals would clearly not produce assortative behaviour. In many animal species, this includes virtually all learning after independence, due to dispersal from their natal area.

A particular group of species where coexistence of closely related species occurs regularly are the haplochromine rock cichlids from East Africa, with about 1,100 species in the three great lakes (Seehausen 2000; Turner et al. 2001). They are especially interesting to study assortative behaviour because this seems to mediate their reproductive isolation. The large number of species suggests that haplochromine cichlids have properties that make them coexist with many closely related species (Salzburger et al. 2005; Seehausen 2006). Moreover, the ecological differentiation between sympatric species pairs seems limited (Seehausen and Bouton 1997; Genner et al. 1999a), thereby minimising the role for ecological competition in frequency-dependent selection. In the laboratory, haplochromine cichlid species can interbreed, and hybrid infertility has not yet been observed (Seehausen 2004; Van der Sluijs et al. 2008). Thus, haplochromine cichlids do not appear to have built up genetic incompatibilities between species which would prevent them from interbreeding, suggesting that reproductive isolation is almost entirely mediated by mate choice. It has been hypothesised that male-male interactions yield negative frequency-dependent selection in cichlids (Seehausen and Schluter 2004). In males, territorial ownership is a requirement for mating, and males will defend their territories vigorously against competing males. Such territories are in general for mating purposes only and are not or very rarely used for feeding (Seehausen and Schluter 2004). Also, males more often have neighbouring territory owners of another species than 
their own species; a pattern predicted when male-male aggression indeed yields negative frequency-dependent selection (Seehausen and Schluter 2004). Moreover, malemale aggression is biased towards the species of males that are likely to compete for the same females, i.e. conspecifics (Lake Malawi: Genner et al. 1999b; Lake Victoria: Dijkstra et al. 2006b; Dijkstra et al. 2007).

How might assortative behaviour in these cichlids be achieved? The exclusive and prolonged maternal care in haplochromine cichlids provides the young with the opportunity for imprinting on their mothers' phenotype. This may produce assortative social preferences. We showed in an interspecific cross-fostering experiment that females of a closely related species pair (species Pundamilia pundamilia and Pundamilia nyererei) from Lake Victoria indeed imprint on their mothers' phenotype (Verzijden and ten Cate 2007). Males seem not to be affected by experience with their mother (Verzijden et al. unpublished), but there are also indications that experience with conspecifics at a later age may allow males to learn the direction of male aggression (Dijkstra et al. 2006a). There is some indication from a study on Astotilapia burtoni that young individuals may learn from their siblings (Crapon de Caprona 1982). The females in an earlier experiment (Verzijden and ten Cate 2007) were not allowed interaction with males from the age of onset of sexual dimorphism onwards. However, interactions among sub-adults may occur frequently in nature, and such experience could potentially diminish the consequences of imprinting for assortative mating.

In this paper, we address the relative influence of experience with the maternal phenotype and the phenotypes of siblings on female mate choice and male rival recognition and the direction of male aggression. We present a cross-fostering study in the closely related, ecologically similar and sympatrically occurring species from Lake Victoria: Mbipia mbipi and Mbipia lutea. They show overlaps in morphology, feeding ecology and time and place of breeding, while male nuptial colouration is distinctly different, which is typical for such closely related species pairs (Seehausen et al. 1998). We obtained crossfostered individuals by swapping full broods between brooding females, as well as swapping almost the full brood or only a few eggs. This way, we test the effect of both imprinting on their mothers' phenotype and learning from their siblings' phenotype. By allowing the broods to grow up as either pure species groups or as mixed species groups, we mimicked possible skewed social experience individuals may encounter while maturing. We tested females for their mate preference and males for their aggression bias. In this study, we did not test for male mate preferences, although they would be interesting to address in future studies.

\section{Materials and methods}

Raising of the treatment clutches

We raised clutches in four different treatment groups, in which mothers, siblings or both could be either a conspecific or heterospecific of the focal individual. We refer to them by abbreviations: the first letter indicates a con- or heterospecific mother, the second letter indicates the siblings: $\mathrm{C}_{\mathrm{mo}} \mathrm{C}_{\mathrm{sib}}$ : conspecific mother, conspecific siblings; $\mathrm{C}_{\mathrm{mo}} \mathrm{H}_{\mathrm{sib}}$ : conspecific mother, heterospecific siblings; $\mathrm{H}_{\mathrm{mo}}$ $\mathrm{C}_{\mathrm{sib}}$ : heterospecific mother, conspecific siblings and $\mathrm{H}_{\mathrm{mo}}$ $\mathrm{H}_{\text {sib }}$ : heterospecific mother and heterospecific siblings (Figs. 1 and 2).

Each of the four treatments consisted of exchanging eggs between brooding females. Broods contained, on average, 22.6 eggs (range $=15-41$ ). In the $\mathrm{C}_{\mathrm{mo}} \mathrm{C}_{\text {sib }}$ treatment, we exchanged the full clutch between two females of the same species. In the $\mathrm{C}_{\mathrm{mo}} \mathrm{H}_{\text {sib }}$ group, we exchanged all but three to six focal eggs between two females of different species. In the $\mathrm{H}_{\mathrm{mo}} \mathrm{C}_{\mathrm{sib}}$ group, we exchanged full clutches between females of different species and, in the $\mathrm{H}_{\mathrm{mo}} \mathrm{H}_{\text {sib }}$ group, we exchanged three to six focal eggs between two females of different species. Mouth brooding takes 3-4 weeks, then the female releases the fry from her mouth. Fry start foraging independently from that moment on. Females of these species display fry guarding behaviour for up to 3 weeks. The brooding females were allowed to show their normal brood care behaviour. After the extended brood care period, the foster mother was removed from the experimental clutch and returned to the stock tank. The clutch was moved to a larger tank when they were between 2 and 3 months old, and remained there until they were sexually mature (approximately 8 months). In nature, sibling groups may not stay together this long, but we decided for this treatment to maximise any possible effect of experience

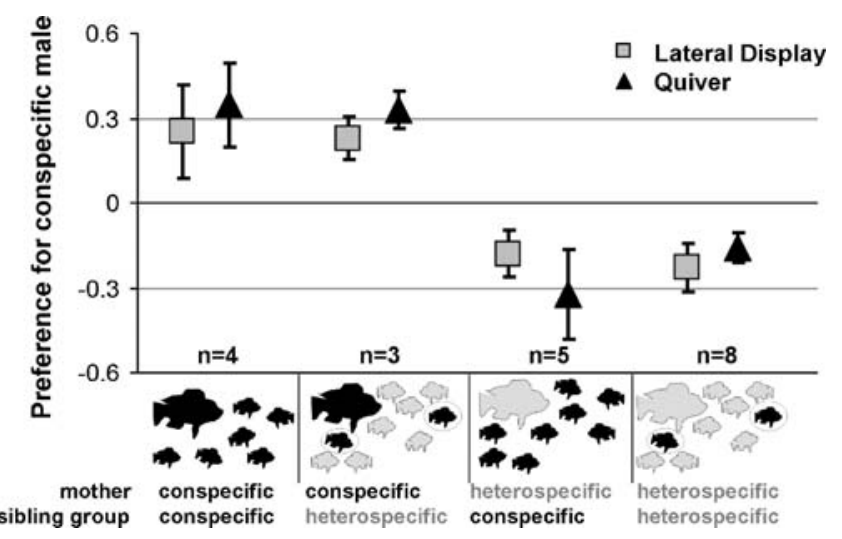

Fig. 1 Female preferences in the different treatment groups. Grey squares are lateral displays, black triangles are quivers; means +/- SE. Scores above zero reflect a preference for conspecific males, scores below zero reflect a preference for heterospecific males 


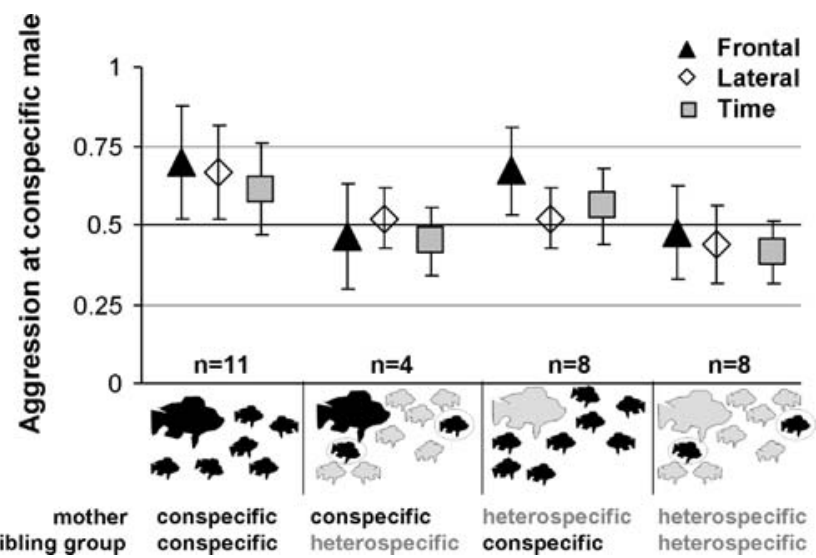

Fig. 2 Male aggression direction of the different treatment groups. Black triangles are frontal behaviour, open diamonds are lateral behaviour, grey squares are time spent interacting; means +/- SE. Scores above 0.5 reflect more aggression to conspecific intruders, scores below 0.5 reflect more aggression to heterospecific intruders

with siblings. After both sexes had fully developed, as judged from their nuptial colouration, but before any breeding had occurred in the tank, the focal females and males were removed from the tank and isolated approximately 2 weeks before testing.

We were able to raise four $\mathrm{C}_{\mathrm{mo}} \mathrm{C}_{\text {sib }}$ clutches, two of each species; four $\mathrm{C}_{\mathrm{mo}} \mathrm{H}_{\text {sib }}$ clutches, only $M$. lutea focal individuals; seven $\mathrm{H}_{\mathrm{mo}} \mathrm{C}_{\text {sib }}$ clutches, two M. mbipi and five M. lutea, and six $\mathrm{H}_{\text {mo }} \mathrm{H}_{\text {sib }}$ clutches, three of each species. Because the $\mathrm{C}_{\text {mo }} \mathrm{H}_{\text {sib }}$ and $\mathrm{H}_{\text {mo }} \mathrm{H}_{\text {sib }}$ groups each yielded only a few individuals per clutch (due to the design of the treatment, average ratio of individuals of the focal species to heterospecific individuals was 1:8), and a few clutches contained either experimental males or females, our sample size was too small to analyse the data on a per-species and per-treatment basis. We therefore merged the data of both species in this experiment.

\section{Female mate choice tests}

We performed 38 successful preference tests on 20 females $\left(4 \mathrm{C}_{\mathrm{mo}} \mathrm{C}_{\mathrm{sib}}, 3 \mathrm{C}_{\mathrm{mo}} \mathrm{H}_{\mathrm{sib}}, 5 \mathrm{H}_{\mathrm{mo}} \mathrm{C}_{\mathrm{sib}}, 8 \mathrm{H}_{\mathrm{mo}} \mathrm{H}_{\mathrm{sib}}\right)$ from 13 broods in total. Each female was tested twice, except for two females who did not become gravid again after their first trial. The test setup and the scoring method was the same as described in Verzijden and ten Cate (2007). The experimental tank $(2 \times 0.5 \times 0.5 \mathrm{~m})$ was divided into three equal compartments by two grids with mesh-size $160 \times 160$ $\mathrm{mm}$. In the outer compartments, a M. mbipi and M. lutea male were placed and bricks were provided as territorial 'rocks'. The mesh size prevented the males from going through the grid, but the females were smaller than the males and were able to swim freely through the tank. In the middle compartment, shelter for the female, in the form of a PVC tube, was provided. Males were matched for standard length as much as possible (average standard length difference was $0.6 \mathrm{~mm}+/-0.09 \mathrm{SE}$, average $0.75 \%$ difference relative to the largest male). Males were placed into the experimental tank 1 day before testing. Twenty stimulus males of each species were (re)combined to 22 stimulus pairs. The average number of times each stimulus pair was used was $1.73+/-0.18$ SE. A gravid female (i.e. ready to lay eggs, as judged by the swelling of the abdomen) was placed in the middle compartment $30-60 \mathrm{~min}$ prior to testing while opaque sheets hid the males from her. Then, the sheets were removed and the female could see and move through the whole tank. A trial lasted $30 \mathrm{~min}$. Courtship interaction often starts at the boundary of a territory and consists of a sequence of displays. During courtship, the male will approach a female when she enters the territory and the male will show a lateral display, followed by a quiver and a lead swim towards the centre of his territory. The female can respond to these behaviours by approaching the male and by following his lead swim. The male will lead the female to the centre of his territory, where spawning may take place (Baerends and Baerendsvan Roon 1950). We scored the type of displays a male gave in a mate choice test and the subsequent approach behaviour of the female. This scoring of courtship behaviour is similar to that described in Seehausen and van Alphen (1998) and Verzijden and ten Cate (2007). In a successful trial, both males displayed at least two quivers and the female responded positively to a quiver twice. If these criteria were not met, testing was later repeated. We tested until each female had two successful trials, with different male pairs and with species and tank side fully counterbalanced. Preference scores used in statistical analysis are the approach ratio to the displays of the conspecific male minus that of the heterospecific male. For instance, for quiver displays: (\# approaches to conspecific male/\# quiver displays conspecific male)-(\# approaches to heterospecific male/\# quiver displays heterospecific male). The resulting scores were therefore on a scale between -1 and 1 , which we used as a measure for preference for conspecific males and heterospecific males, respectively.

\section{Male aggression bias tests}

We tested $11 \mathrm{C}_{\mathrm{mo}} \mathrm{C}_{\text {sib }}$ males, $4 \mathrm{C}_{\mathrm{mo}} \mathrm{H}_{\text {sib }}$ males, $8 \mathrm{H}_{\mathrm{mo}} \mathrm{C}_{\mathrm{sib}}$ males and $8 \mathrm{H}_{\mathrm{mo}} \mathrm{H}_{\text {sib }}$ males from a total of 19 broods. Each male was tested twice, except for two males, one in the $\mathrm{H}_{\mathrm{mo}} \mathrm{C}_{\text {sib }}$ group and one in the $\mathrm{C}_{\mathrm{mo}} \mathrm{H}_{\text {sib }}$ group, who died before the end of the experiment. The focal male was placed $48 \mathrm{~h}$ prior to testing in the experimental tank $(2 \times$ $0.5 \times 0.5 \mathrm{~m}$ ), which was divided in half with the use of two opaque PVC sheets. Each male also had a 'neighbour male': a smaller male cichlid of a different genus placed at the end of the tank behind a Plexiglas sheet. We placed this 
male in the experimental tank to enhance territoriality (Dijkstra et al. 2006b). At the time of testing, two cylinders were placed in the experimental space of the focal male. In these cylinders, we placed a male of each species, matched for standard length to each other (mean difference in standard length was $0.4 \mathrm{~mm}+/-0.06 \mathrm{SE}$, average $0.8 \%$ difference relative to the largest male). Thirty two M. mbipi and $34 \mathrm{M}$. lutea males were (re)combined to 44 stimuli pairs. The average number of times each stimulus pair was used was $1.59+/-0.13 \mathrm{SE}$. Observations started right after placement of the cylinders and lasted $20 \mathrm{~min}$ after the start of aggressive interactions. We recorded the following behaviours: frontal displays, bites, lateral displays and quivers. Territories in these limnetic species are only for reproductive means; feeding occurs outside the territories (Seehausen and Schluter 2004). Adult males defend territories in a lek-like setting. Aggressive interactions usually will take place at the border of the territories. There are two categories of behavioural display that we scored during observations of the aggressive interaction observations. The first category consists of attack-like displays, called frontal displays, which precedes the biting of each other's mouths, used at the border of a territory. During frontal displays, males line up head to head. During bites, males grab each other's mouths and pull back and forth. In our set-up, males could not physically bite each other, but they bit the Plexiglas separating them. We added up the number of frontal displays and bites to obtain one measure for the frontal aggressive behaviour, as some males never performed bites and some never performed frontal displays prior to attacking, while others performed both. The other category consists of lateral displays, which may be followed by quivers. During a lateral display, the male extends his dorsal, anal and pelvic fins and positions himself such that his flank is in front of the head of the opponent. The quiver, finally, is usually preceded by a lateral display. The male has the same position as in the lateral display, and the fins are equally extended, but a fast shaking movement of the body is made. Lateral displays and quivers are also sequentially connected behaviours, and again, some males never performed quivers or lateral displays. Adding up lateral displays and quivers gave one measure for the lateral behaviour. Aggression bias as examined in the statistical analysis was the proportion of the given behaviours directed at the conspecific male, which therefore yields a score between 0 and 1 , with a score above 0.5 indicating an aggression bias to males of their own species.

\section{Statistical analysis}

All statistical analyses were conducted using R statistical software (R Development Core Team 2005). We fitted generalised linear mixed effect models (GLMMs). All models were hierarchically nested, correcting for any pseudoreplication: broods within treatment and individuals (two trials) within broods. We had two fixed effects which each had two levels: foster mother (conspecific or heterospecific) and siblings (conspecific or heterospecific). If the fixed effect of foster mother is significant in the model, the behaviour of the males or females is affected by the phenotype of the (foster) mother that raised them. If the fixed effect of siblings is significant in the model, the behaviour of the males or females is influenced by the phenotypes of their (foster) siblings. An interaction would indicate that each of the treatments had a different effect in each combination. We stepwise deleted factors from a fully saturated model until the minimal adequate GLMM was found, but always keeping repeated measures for each individual as a random factor.

Depending on the nature of the data, we used the Gaussian (standard normal) or the binomial distribution to fit our models. For data analysed with Gaussian distribution, we report $F$-tests on the variance, while we report a $X^{2}$ test on the deviance, as appropriate for binomial data. At each step in the model simplification, we verified that the assumptions of normal distribution of the errors and constant variance were met, by visual inspection of the concerned plots, and for over dispersion when the binomial distribution was used. We did not test for significant female mate preferences or male aggression biases per treatment group due to the limited sample size in each separate group. Also, we cannot test for species differences due to the limited sample size. Therefore, we pooled the data from the two species. Inspection of the data obtained from both types of tests (female mate choice and male aggression bias) showed that data points from M. mbipi fell safely within the range of $M$. lutea, for which we obtained more data.

\section{Results}

Female mate choice tests

Table 1 presents the data analysis from the GLMMs. We found a significant effect of the factor foster mother (conspecific or heterospecific) on the mate choice behaviour of the females (Fig. 1). Females were more likely to approach a displaying male if he was of the same species as their foster mother. This was true on both the level of lateral displays and on the quiver displays. Females did not spend significantly more time with the male of the same species of their foster mother. There was no effect of siblings in either measure (Fig. 1). We tested for an effect of treatment on which male a female visited first in a trial. This first visit was more often than random to the male of the foster 
Table 1 Results of the GLMM's of analysis of the female preference tests. The effects are listed in reverse order of deletion from the model

The final model is in italic.

\begin{tabular}{|c|c|c|c|c|}
\hline Response variable & Explanatory variable & $F / X^{2}$ & $\mathrm{df}$ & $P$ \\
\hline \multirow[t]{7}{*}{ Lateral display } & $\begin{array}{l}\text { Distribution: Gaussian } \\
\text { Fixed effects: }\end{array}$ & & & \\
\hline & Mother & 18.11 & 1.18 & $<0.001$ \\
\hline & Siblings & 0.34 & 1.17 & 0.57 \\
\hline & Mother $\times$ siblings & 0.01 & 1.16 & 0.94 \\
\hline & Random effect: & & & \\
\hline & Individual & Lh. ratio $=0.1301$ & 0.717 & \\
\hline & Brood & Lh. ratio $<0.0001$ & 1 & \\
\hline \multirow[t]{7}{*}{ Quiver display } & $\begin{array}{l}\text { Distribution: Gaussian } \\
\text { Fixed effects: }\end{array}$ & & & \\
\hline & Mother & 29.63 & 1.18 & $<0.001$ \\
\hline & Siblings & 0.80 & 1.17 & 0.38 \\
\hline & Mother $\times$ siblings & 0.005 & 1.16 & 0.94 \\
\hline & Random effect: & & & \\
\hline & Individual & Lh. ratio $<0.0001$ & 1 & \\
\hline & Brood & Lh. ratio $<0.0001$ & 1 & \\
\hline \multirow[t]{7}{*}{ First visit } & $\begin{array}{l}\text { Distribution: binomial } \\
\text { Fixed effects: }\end{array}$ & & & \\
\hline & Mother & 6.32 & 1 & 0.01 \\
\hline & Siblings & 0.15 & 1 & 0.67 \\
\hline & Mother $\times$ siblings & 0.02 & 1 & 0.99 \\
\hline & Random effect: & & & \\
\hline & Individual & 0.1677 & 1 & 0.6821 \\
\hline & Brood & 0 & 1 & 1 \\
\hline \multirow[t]{8}{*}{ Time spent } & Distribution: binomial & & & \\
\hline & Fixed effects: & & & \\
\hline & Mother & 2.81 & 1 & 0.09 \\
\hline & Siblings & 1.02 & 1 & 0.31 \\
\hline & Mother $\times$ siblings & 0.06 & 1 & 0.81 \\
\hline & Random effect: & & & \\
\hline & Individual & $<0.001$ & 1 & 0.999 \\
\hline & Brood & 0 & 1 & 1 \\
\hline
\end{tabular}

species (Table 1). Again, siblings had no effect on the choice of first visit. Additionally, we tested if the male a female visited first in a trial was predictive of her approach rate to either lateral display or quiver display. There was a significant relation between first visit and differential approach rate to the quiver display $\left(X^{2}=5.7, \mathrm{df}=1, P=\right.$ $0.017)$, but there was no significant relation with lateral display $\left(X^{2}=2.75, \mathrm{df}=1, P=0.09\right)$.

Male aggression bias tests

Table 2 presents the data analysis from the GLMMs. We found an effect of sibling group, but not mother, on the direction of aggression by the males (Fig. 2). This was significant in all three parameters: the proportion of frontal behaviour directed to the conspecific intruder, the proportion lateral behaviour and the proportion of time spent interacting with the conspecific intruder. Males with conspecific siblings showed more displays towards and spent more time interacting with the conspecific intruder than males raised with heterospecific siblings. Males displayed more often with frontal behaviour than with lateral behaviour (paired $t$ test: $t_{36}=5.39, P<0.001$, mean of the differences: $48.2+/-8.9 \mathrm{SE})$. The random effect 'individual' was significant in both the frontal behaviour and lateral behaviour; we therefore subsequently tested if such a 'trial effect' was different between the treatments. We did not find such effects (Table 2).

\section{Discussion}

Our data show effects of experience on both female choice and male-male aggression in these cichlid species. The females raised in our experiment developed a sexual preference for males of their mothers' phenotype, so we conclude that the females imprinted on their mother. We tested females when they were sexually mature, at which time their (foster) siblings were also fully developed and their brothers thus showed nuptial colouration. In two of the four treatment groups, $\mathrm{C}_{\mathrm{mo}} \mathrm{H}_{\text {sib }}$ and $\mathrm{H}_{\mathrm{mo}} \mathrm{H}_{\text {sib }}$, females therefore had the opportunity to interact with males of a 
Table 2 Results of the GLMM's of analysis of the male aggression tests
The effects are listed in reverse order of deletion from the model. The final model is in italic. The final models testing for the effect of trial also show non-significant interaction effects, but the deletion of the interaction effect did not make the trial effect significant. We therefore kept the full model as final, showing no effects of trial.

\begin{tabular}{|c|c|c|c|c|}
\hline Response variable & Explanatory variable & $X^{2}$ & $\mathrm{df}$ & $P$ \\
\hline \multirow[t]{7}{*}{ Frontal behaviour } & Fixed effects: & & & \\
\hline & Siblings & 13.17 & 1 & $<0.001$ \\
\hline & Mother & 0.07 & 1 & 0.80 \\
\hline & Mother $\times$ siblings & 0.0003 & 1 & 0.99 \\
\hline & Random effect: & & & \\
\hline & Individual & 8.91 & 1 & 0.0028 \\
\hline & Brood & 0 & 1 & 1 \\
\hline \multirow[t]{7}{*}{ Lateral behaviour } & Fixed effects & & & \\
\hline & Siblings & 17.59 & 1 & $<0.001$ \\
\hline & Mother & 0 & 1 & 1 \\
\hline & Mother $\times$ siblings & 0 & 1 & 1 \\
\hline & Random effect: & & & \\
\hline & Individual & 32.41 & 1 & $<0.001$ \\
\hline & Brood & 0 & 1 & 1 \\
\hline \multirow[t]{7}{*}{ Time spent } & Fixed effects: & & & \\
\hline & Siblings & 10.767 & 1 & 0.001 \\
\hline & Mother & 1.5044 & 1 & 0.22 \\
\hline & Mother $\times$ siblings & 0.076 & 1 & 0.78 \\
\hline & Random effect: & & & \\
\hline & Individual & 0 & 1 & 1 \\
\hline & Brood & 0 & 1 & 1 \\
\hline \multicolumn{5}{|l|}{ Effect of trial: } \\
\hline \multirow[t]{3}{*}{ FD-B } & Trial & 2.06 & 1 & 0.11 \\
\hline & Siblings & 15.52 & 1 & $<0.001$ \\
\hline & Trial $\times$ siblings & 0.01 & 1 & 0.94 \\
\hline \multirow[t]{3}{*}{ LDQ } & Trial & 0.15 & 1 & 0.67 \\
\hline & Siblings & 7.95 & 1 & 0.004 \\
\hline & Trial $\times$ siblings & 0.01 & 1 & 0.90 \\
\hline
\end{tabular}

different species than that of their foster mother, but this caused no shift in preference towards the species of their siblings. So, despite ample opportunity for interaction with their (foster) siblings, this did not affect their mate preference. Our results thus show that imprinted preferences can be robust against later social experiences. In a previous cross-fostering study on another species pair, females of $P$. pundamilia and $P$. nyererei showed the same effect of foster mother on their mate preferences (Verzijden and ten Cate 2007). The high similarity between the results of both studies supports the idea that the closely related haplochromine cichlid species of Lake Victoria share this imprinting behaviour. Because females imprint on their mothers' phenotype, rather than on other individuals, there is a strong link between the phenotype of the female and her preference for males with a similar phenotype (Verzijden et al. 2005). This is a condition for strong assortative mating patterns, critical for both a sympatric speciation scenario and reinforcement after secondary contact (e.g. Felsenstein 1981; Servedio 2000).

In contrast to the females, males adjusted the direction of their territorial defence depending on the composition of the brood they grew up in. Males showed more aggression to heterospecific males if they had been raised with heterospecific sibling males, while the species of foster mother had no significant effect on the parameters we measured. The males' aggression, thus, was not directed at their own phenotype at all times but, instead, at males similar to the males they were raised with. Under normal conditions (i.e. not when cross fostered), siblings would resemble a males' own phenotype more than in our mixedbroods cross fostering. However, offspring share, on average, more of the genotype, and phenotype, with their mother than with their siblings. Rival imprinting on the mothers' phenotype would thus more likely lead to speciesassortative aggression than when males imprint on their siblings. Although haplochromine cichlids show sexual dimorphism, the sexes are apparently similar enough to generalise from the mother's phenotype to the male's phenotype, as shown by the females in this study and in Verzijden and ten Cate (2007).

Species differences in the effects of imprinting could not be tested for with the data obtained in this study. Although we did not find any species differences in our previous cross fostering study (Verzijden and ten Cate 2007), a difference in early learning between closely related species was shown in studies on birds (Slagsvold et al. 2002; Hansen and Slagsvold 2003). 
Sexually mature males are brightly coloured, while females are mostly yellow or brown-grey. However, there is some difference in the colouration of females between the two species, and this difference is also enhanced during mouth brooding (Seehausen et al. 1998). The young females may thus possibly have learned about their mothers' colour, but it is also possible that olfactory cues have been imprinted on. As both colour and olfactory cues could be used at all stages of the experiment, we cannot conclude which cue served as imprinting stimulus. While we can conclude that females learned about their mother in the first few weeks of their lives, either during mouth brooding or while the mother guards the fry, when the males learned cannot be assessed from this experiment.

If, under natural conditions, males learned while hatching, or shortly thereafter, they are likely to imprint on closely related individuals because the other hatchlings are at least half-siblings. However, although they shared the time in the mouth of their (foster) mother with their foster siblings, it is not very likely that they learned about them at that time. During this stage, there are no discernable visual differences between fry (Fernald and Hirata 1979), and the available light in the mouth of the mother is likely to be quite limited. This implies that if the fry learn about their siblings at this stage, they probably would have to rely on olfactory cues. However, the olfactory cues in the mothers' mouth are also likely to be largely influenced by the mother herself. Because we found no influence of species of foster mother on the males' behaviour, it seems unlikely that males use this experience while hatching. At a later stage, the females of these cichlids also provide care for their offspring after hatching by taking them back into their mouth with approaching danger (another fish or, in our experiment, an animal care taker). Fry then rely on visual cues to approach the mouth of the female (Baerends 1993; Russock 1999). The interaction with their siblings at this time may provide them with the opportunity to learn about their fellow siblings, which would ensure that they learn about closely related individuals. While, in our experiment, the brood stayed in one tank exclusively, in nature, it is largely unknown how and if young cichlids aggregate from the time their mother leaves them alone until the time they become territorial. However, schools of same-size fry can often be seen in shallow water at rocky shores (personal observation, MNV), and mixed species shoals of nonbreeding males have been observed (Seehausen et al. 1998; personal communication, M.E. Maan). If males establish their aggression biases at that stage, those biases are not likely to be assortative because the individuals they encounter at that time are likely to be from different species. However, this scenario would not explain the species-assortative behaviour found in wild males of several reproductively isolated populations (Dijkstra et al. 2006b; Dijkstra et al. 2007). Interestingly, interactions with males of a different species do not necessarily result in a lack of an aggression bias for their own phenotype and may even bias aggression towards their own phenotype (Dijkstra et al. 2006a). This suggests that the development of aggression biases is sensitive to the context of the interactions between males. However, this is, at the moment, speculative and more experiments are needed.

Lake Victoria rock cichlids have been proposed as a possible case of sympatric speciation. This was postulated on the basis of distribution patterns of many species pairs, where one of the two species is nested within the distribution of the other (Seehausen and van Alphen 1999). The species pair in this study also shows such nested distribution (Seehausen et al. 1998). Conditions allowing sympatric speciation are quite strict, calling for strong assortative mating mediating reproductive isolation at a very early stage of divergence and a source of negative frequency-dependent selection driving the divergence. The alternative scenario leading to the observed distribution pattern of related species is secondary contact after allopatric divergence (Bouton 2000). This still requires reproductive isolation, but frequency-dependent selection does not need to drive the divergence. While the imprinting behaviour of the females could cause strong assortative mating patterns in both scenarios of speciation (Verzijden et al. 2005; Servedio et al. 2008), the male-male interactions are not assortative at all times. The cross-fostering experiment may be an unlikely situation in nature; however, at an incipient speciation stage, hybridisation may be more common, and mixed broods resembling our experiment can easily occur. We therefore propose that the developmental mechanism for male aggressive behaviour is unlikely to produce enough frequency-dependent selection at the earlier stages of speciation to help drive sympatric speciation, although it need not hamper speciation either.

In summary, the results of our experiment indicate that females of the species pair M. mbipi and M. lutea sexually imprint on their mothers' phenotype. This is consistent with the findings in a previous cross-fostering study with the other species pair P. pundamilia and P. nyererei (Verzijden and ten Cate 2007). The similarity of the results indicates that the developmental mechanisms of assortative behaviour may be shared between the highly related cichlid species of Lake Victoria. Secondly, the development of assortative male-male aggressive behaviour is mediated by experience with individuals other than the mother, possibly their siblings in nature. Learning about siblings would provide males in reproductively isolated species with an aggression bias for their own phenotype, but in hybridising populations, this may most likely result in a lack of an aggression bias. The development of assortative behaviour of females, but not of males, therefore, creates favourable 
conditions for sympatric speciation. However, in a scenario involving secondary contact after allopatric divergence, the behaviour of both sexes contributes to species coexistence.

Acknowledgments We thank Mohammed Haluna, Kees Hofker, Mhoja Kayeba, Martine Maan, Ole Seehausen, Inke van der Sluijs and Anne de Vries for help at various stages of the experiment. Comments by Katharina Riebel, Michael Ryan and three anonymous reviewers greatly improved this manuscript. CtC acknowledges support by a Lorentz fellowship at the Netherlands Institute for Advanced Study (Wassenaar, Netherlands).This experiment was approved by the university committee for animal experiments under licence number: DEC06110. Financial support came from Netherlands Organisation for Scientific Research (NWO) (ALW-810.64.012) and Lucie Burgers Foundation for Comparative Behaviour Research Arnhem, The Netherlands.

Open Access This article is distributed under the terms of the Creative Commons Attribution Noncommercial License which permits any noncommercial use, distribution, and reproduction in any medium, provided the original author(s) and source are credited.

\section{References}

Alatalo RV, Gustafsson L, Lundberg A (1994) Male coloration and species recognition in sympatric flycatchers. Proc R Soc Lond B Biol Sci 256:113-118 DOI 10.1098/rspb.1994.0057

Arnegard ME, Kondrashov AS (2004) Sympatric speciation by sexual selection alone is unlikely. Evolution 58:222-237

Baerends GP (1993) A comparative-study of stimulus selection in the filial following response of fry of substrate spawning cichlid fish. Behaviour 125:79-155

Baerends GP, Baerends-van Roon JM (1950) An introduction to the study of the ethology of cichlid fishes. Behavior 1:1-235 (Suppl)

Beltman JB, Metz JAJ (2005) Speciation: more likely through a genetic or through a learned habitat preference? Proc R Soc Lond B Biol Sci 272:1455-1463 DOI 10.1098/rspb.2005.3104

Bereczkei T, Gyuris P, Weisfeld GE (2004) Sexual imprinting in human mate choice. Proc R Soc Lond B Biol Sci 271:1129-1134

Bouton N (2000) Progressive invasion and allopatric speciation can also explain distribution patterns of rock-dwelling cichlids from southern Lake Victoria: a comment on Seehausen and van Alphen (1999). Ecol Lett 3:166-169

Coyne JA, Orr HA (2004) Speciation. Sinauer, Sunderland

Crapon de Caprona MD (1982) The influence of early experience on preferences for optical and chemical cues produced by both sexes in the cichlid fish Haplochromis burtoni (Astatotilapia burtoni, Greenwood 1979). Z Tierpsychol 58:329-361

Dieckmann U, Doebeli M (1999) On the origin of species by sympatric speciation. Nature 400:354-357 DOI 10.1038/22521

Dijkstra PD, Seehausen O, Fraterman RE, Groothuis TGG (2006a) Learned aggression biases in Lake Victoria cichlid fish. Know thine enemy: intrasexual selection and sympatric speciation in Lake Victoria cichlid fish, PhD Thesis P.D. Dijkstra, Groningen

Dijkstra PD, Seehausen O, Gricar BLA, Maan ME, Groothuis TGG (2006b) Can male-male competition stabilize speciation? A test in Lake Victoria haplochromine cichlid fish. Behav Ecol Sociobiol 59:704-713 DOI 10.1007/s00265-005-0100-1

Dijkstra PD, Seehausen O, Pierotti MER, Groothuis TGG (2007) Male-male competition and speciation: aggression bias towards differently coloured rivals varies between stages of speciation in a Lake Victoria cichlid species complex. J Evol Biol 20:496-502 DOI 10.1111/j.1420-9101.2006.01266.x
Engeszer RE, Ryan MJ, Parichy DM (2004) Learned social preference in zebrafish. Curr Biol 14:881-884 DOI 10.1016/j.cub.2004.04.042

Felsenstein J (1981) Skepticism towards Santa Rosalia, or why are there so few kinds of animals? Evolution 35:124-138 DOI 10.2307/ 2407946

Fernald RD, Hirata NR (1979) Ontogeny of social-behavior and body coloration in the African cichlid fish Haplochromis burtoni. Z Tierpsychol 50:180-187

Genner MJ, Turner GF, Barker S, Hawkins SJ (1999a) Niche segregation among Lake Malawi cichlid fishes? Evidence from stable isotope signatures. Ecol Lett 2:185-190 DOI 10.1046/ j.1461-0248.1999.00068.x

Genner MJ, Turner GF, Hawkins SJ (1999b) Resource control by territorial male cichlid fish in Lake Malawi. J Anim Ecol 68:522529

Hansen BT, Slagsvold T (2003) Rival imprinting: interspecifically crossfostered tits defend their territories against heterospecific intruders. Anim Behav 65:1117-1123 DOI 10.1006/anbe.2003.2146

Kendrick KM, Hinton MR, Atkins K, Haupt MA, Skinner JD (1998) Mothers determine sexual preferences. Nature 395:229-230 DOI $10.1038 / 26129$

Kirkpatrick M, Ravigne V (2002) Speciation by natural and sexual selection: models and experiments. Am Nat 159:S22-S35

Mikami OK, Kohda M, Kawata M (2004) A new hypothesis for species coexistence: male-male repulsion promotes coexistence of competing species. Popul Ecol 46:213-217 DOI 10.1007/ s10144-004-0189-5

R Development Core Team (2005) R: A language and environment for statistical computing. In, 2.2.1 edn. R Foundation for Statistical Computing, Vienna, Austria. http://www.R-project.org.

Riebel K (2003) The "mute" sex revisited: vocal production and perception learning in female songbirds. In: Slater PJB, Rosenblatt JS, Snowdon CT, Roper TJ, Naguib M (eds) Advances in the study of behavior. vol. 33. Academic, London, pp 49-86

Ritchie MG (2000) The inheritance of female preference functions in a mate recognition system. Proc $\mathrm{R}$ Soc Lond B Biol Sci 267:327-332

Roelofs W, Glover T, Tang XH, Sreng I, Robbins P, Eckenrode C, Lofstedt C, Hansson BS, Bengtsson BO (1987) Sex-pheromone production and perception in European corn-borer moths is determined by both autosomal and sex-linked genes. Proc Natl Acad Sci U S A 84:7585-7589

Rueffler C, Van Dooren TJM, Leimar O, Abrams PA (2006) Disruptive selection and then what? Trends Ecol Evol 21:238245 DOI 10.1016/j.tree.2006.03.003

Russock HI (1999) Filial social bond formation in fry of the maternal mouthbrooding tilapia (Pisces: Cichlidae): a comparative study. Behaviour 136:567-594 DOI 10.1163/156853999501478

Salzburger W, Mack T, Verheyen E, Meyer A (2005) Out of Tanganyika: genesis, explosive speciation, key-innovations and phylogeography of the haplochromine cichlid fishes. BMC Evol Biol 5:17 DOI 10.1186/1471-2148-5-17

Seehausen O (2000) Explosive speciation rates and unusual species richness in haplochromine cichlid fishes: effects of sexual selection. In: Rossiter A, Kawanabe $\mathrm{H}$ (eds) Advances in ecological research. vol. 31. Academic, London, pp 237-274

Seehausen O (2004) Hybridization and adaptive radiation. Trends Ecol Evol 19:198-207 DOI 10.1016/j.tree.2004.01.003

Seehausen O (2006) African cichlid fish: a model system in adaptive radiation research. Proc R Soc Lond B Biol Sci 273:1987-1998 DOI 10.1098/rspb.2006.3539

Seehausen O, Bouton N (1997) Microdistribution and fluctuations in niche overlap in a rocky shore cichlid community in Lake Victoria. Ecol Freshw Fish 6:161-173

Seehausen O, van Alphen JJM (1998) The effect of male coloration on female mate choice in closely related Lake Victoria cichlids 
(Haplochromis nyererei complex). Behav Ecol Sociobiol 42:1-8 DOI 10.1007/s002650050405

Seehausen O, Lippitsch E, Bouton N, Zwennes H (1998) Mbipi, the rock-dwelling cichlids of Lake Victoria: description of three new genera and fifteen new species (Teleostei). Ichthyol Explor Freshw 9:129-228

Seehausen O, Schluter D (2004) Male-male competition and nuptialcolour displacement as a diversifying force in Lake Victoria cichlid fishes. Proc R Soc Lond B Biol Sci 271:1345-1353 DOI 10.1098/rspb.2004.2737

Seehausen O, van Alphen JM (1999) Can sympatric speciation by disruptive sexual selection explain rapid evolution of cichlid diversity in Lake Victoria? Ecol Lett 2:262-271 DOI 10.1046/ j.1461-0248.1999.00082.x

Servedio MR (2000) Reinforcement and the genetics of nonrandom mating. Evolution 54:21-29

Servedio MR, Saether SA, Saetre G (2008) Reinforcement and learning. Evol EcolDOI 10.1007/s10682-007-9188-2

Shaw KL (2000) Interspecific genetics of mate recognition: inheritance of female acoustic preference in Hawaiian crickets. Evolution 54:1303-1312

Slagsvold T, Hansen BT, Johannessen LE, Lifjeld JT (2002) Mate choice and imprinting in birds studied by cross-fostering in the wild. Proc R Soc Lond B Biol Sci 269:1449-1455 ten Cate C, Vos DR (1999) Sexual imprinting and evolutionary processes in birds: a reassessment. Adv Study Behav 28:1-31

Turner GF, Seehausen O, Knight ME, Allender CJ, Robinson RL (2001) How many species of cichlid fishes are there in African lakes? Mol Ecol 10:793-806 DOI 10.1046/j.1365-294x.2001.01200.x

Tynkkynen K, Kotiaho JS, Luojumaki M, Suhonen J (2005) Interspecific aggression causes negative selection on sexual characters. Evolution 59:1838-1843

Van der Sluijs I, van Dooren TJM, van Alphen JJM, Seehausen O (2008) A test of fitness consequences of hybridization in sibling species of Lake Victoria cichlid fish. J Evol Biol 21:480-491

van Doorn GS, Dieckmann U, Weissing FJ (2004) Sympatric speciation by sexual selection: a critical reevaluation. Am Nat 163:709-725

Verzijden MN, Lachlan RF, Servedio MR (2005) Female mate-choice behavior and sympatric speciation. Evolution 59:2097-2108 DOI 10.1554/04-567.1

Verzijden MN, ten Cate C (2007) Early learning influences species assortative mating preferenes in Lake Victoria cichlid fish. Biol Lett 3:134-136 DOI 10.1098/rsbl.2006.0601

Vos DR (1994) Sex recognition in zebra finch males results from early experience. Behaviour 128:1-14

Wong BBM, Candolin U (2005) How is female mate choice affected by male competition? Biol Rev 80:559-571 